\title{
Finding words for feelings: The relationship between personality disorders and alexithymia
}

\author{
Chiara De Panfilis ${ }^{\mathrm{a}, \mathrm{b}, *}$, Paolo Ossola ${ }^{\mathrm{a}}$, Matteo Tonna ${ }^{\mathrm{b}}$, Lorena Catania ${ }^{\mathrm{c}}$, Carlo Marchesi ${ }^{\mathrm{a}, \mathrm{b}}$ \\ ${ }^{a}$ Unit of Psychiatry, Department of Neuroscience, University of Parma, Italy \\ ${ }^{\mathrm{b}}$ Mental Health Department, Local Health Agency, Parma, Italy \\ c Villa Rosa Hospital, Modena, Italy
}

\section{A R T I C L E I N F O}

Article history:

Received 4 August 2014

Received in revised form 27 October 2014

Accepted 30 October 2014

Available online 19 November 2014

\section{Keywords:}

Alexithymia

Personality disorders

External oriented thinking

Comorbid psychopathology

\begin{abstract}
A B S T R A C T
This study examined whether personality disorders (PDs) are associated with alexithymic features at varying levels of comorbid psychopathology distress. 167 psychiatric outpatients completed the Toronto Alexithymia Scale (TAS) and the General Severity Index (GSI) of the SCL90-revised. Bootstrapping analyses were performed to test whether the PD/alexithymia relationship was moderated by psychopathology distress (GSI). The overall number of PD criteria was associated with cognitive aspects of alexithymia (i.e., Externally Oriented Thinking, EOT) only at low/moderate levels of distress. Borderline criteria predicted EOT only when distress was low, while avoidant and dependent criteria were independently related with EOT. No association was found between other PDs and alexithymia facets. Thus, within clinical samples the alexithymia/PD association is mainly explained by comorbid psychopathology; however, individuals with avoidant, dependent and borderline features might have a specific difficulty with focusing on internal reality, even when their current symptom distress is low.
\end{abstract}

(C) 2014 Elsevier Ltd. All rights reserved.

\section{Introduction}

Alexithymia refers to an altered processing of emotions that results in difficulty identifying/communicating one's own feelings and in a concrete style of relating to others (Taylor, Bagby, \& Parker, 1997). These affective (i.e., impaired emotional awareness and expression) and cognitive (i.e., externally oriented thinking) components of alexithymia prevent from understanding and representing the affects and mental states of both the self and the other, thereby interfering with successful mentalization (Choi-Kain \& Gunderson, 2008; Di Maggio et al., 2013; Grynberg, Luminet, Corneille, Grèzes, \& Berthoz, 2010; Moriguchi et al., 2007; Taylor et al., 1997).

Given the clinical relevance of emotional and mentalizing dysfunctions among patients with personality disorders (PDs), several studies investigated the relationship between alexithymia and PDs. However, results are mixed both in terms of which specific PDs show increased alexithymia, and of the nature of the alexithymic difficulties eventually endorsed by PD patients. Alexithymia has

\footnotetext{
* Corresponding author at: Università degli Studi di Parma, Dipartimento di Neuroscienze, Unità di Psichiatria, c/o Ospedale Maggiore, pad. 21 Braga, viale A Gramsci 14, 43126 Parma, Italy. Tel.: +39 0521033594; fax: +39 0521347047.

E-mail address: chiara.depanfilis@unipr.it (C. De Panfilis).
}

been associated with the presence of personality disturbances in general (Berenbaum, 1996; De Panfilis et al., 2008; Grabe, Spitzer, \& Freyberger, 2001), with Cluster A or C PD only (Bach, de Zwaan, Ackard, Nutzinger, \& Mitchell, 1994; Coolidge, Estey, Segal, \& Marle, 2013; Nicolò et al., 2011; Sexton, Sunday, Hurt, \& Halmi, 1998), or with borderline personality disorder (BPD) (Domes, Grabe, Czieschnek, Heinrichs, \& Herpertz, 2011; Guttman \& Laporte, 2002; Joyce, Fujiwara, Cristall, Ruddy, \& Ogrodniczuk, 2013; New et al., 2012). In addition, PDs have been linked with affective components of alexithymia only (Di Maggio et al., 2013), with both affective and cognitive alexithymia (Domes et al., 2011; New et al., 2012), or with increased alexithymia in general (Coolidge et al., 2013; Honkalampi, Hintikka, Antikainen, Lehtonen, \& Viinamaki, 2001; Nicolò et al., 2011).

A potential reason for these discrepancies may rely on the different ways used to control for comorbid psychopathology when examining the $\mathrm{PD} /$ alexithymia relationship, which is a necessary step given the well-known association between "affective" alexithymic deficits (i.e., difficulty recognizing and expressing feelings) and current psychiatric disorders (e.g. Eating, Substance Use, Anxiety and Mood Disorders) (Marchesi, Bertoni, Cantoni, \& Maggini, 2008; Marchesi, Brusamonti, \& Maggini, 2000; Marchesi, Fontò, Balista, Cimmino, \& Maggini, 2005; Marchesi, Ossola, Tonna, \& De 
Panfilis, 2014; Saarijavi, Salminen, \& Toikka, 2001; Taylor et al., 1997). While most studies employing clinical populations did not control for the severity of concurrent psychiatric symptoms (De Panfilis et al., 2008; Domes et al., 2011; Joyce et al., 2013), other studies deal with such issue by including non-clinical samples only (Coolidge et al., 2013) or selected PD samples with no current comorbidity (New et al., 2012), which, however, limits the generalizability of the findings to 'real world' PD patients.

Importantly, after controlling for current psychopathology severity, overall alexithymia was unrelated with total PD criteria among treatment-seeking psychiatric outpatients (Di Maggio et al., 2013), suggesting that PD patients' alexithymic deficits are accounted for by the emotional distress arising from their comorbid symptoms. However, since most patients with PD are driven to seek treatment by their concurrent psychological distress, within clinical samples the robust link between alexithymia and current psychopathology might also disguise any correlation between alexithymia and PD. For instance, Honkalampi et al. (2001) found that whereas alexithymia was unrelated with Cluster C PD among patients with active major depression, Cluster C comorbidity was nonetheless associated with lesser alexithymia decrease over a 6-month follow-up than pure major depression only. This suggests that the specific relationship between alexithymia and PD was disguised, during the acute depressive episode, by the stronger correlation between symptom severity and increasing alexithymia features. Thus, although some PD could be characterized by specific alexithymic difficulties, such association could be obscured by the presence of severe concurrent symptom distress, and can become apparent only at milder levels of psychopathology.

Investigating whether (and which) alexithymic features are associated with PDs at varying levels of symptom severity has important treatment implications. If no association between PD and alexithymia is detected at any degree of current psychopathology distress, it would mean that PD patients are impaired in their ability to recognize/communicate/analyze emotions only because of their comorbid psychopathology; thus, such social-cognitive difficulties could be reduced by more vigorous efforts at decreasing their distress. Conversely, if alexithymia is specifically associated with PD at low levels of psychopathology, treatment should directly address PD patients' difficulty to accurately process their own affects.

Therefore, this exploratory study examined whether (and which) PDs are associated with overall alexithymia and its affective and cognitive components depending on different levels of current psychopathology severity. Based on previous research, we expected that for patients with high symptom distress alexithymia (and, particularly, its affective component) might not be related with PD features, but only with the current state of symptom severity; however, for individuals with low psychopathology distress, a specific relationship between some PDs and definite components of alexithymia could emerge.

\section{Methods}

\subsection{Sample}

The study included 167 outpatients consecutively seeking treatment at an Italian public Psychiatry Unit. Exclusion criteria were: (1) younger than 18 and older than 65 years old; (2) cognitive impairment or language barriers interfering with the capacity to understand interviews or questionnaires; (3) a diagnosis of schizophrenia, other psychotic disorders (except brief psychotic episodes) or psychotic mood episodes due to their impact on cognitive and affective processing; (4) current substance intoxication or withdrawal. After giving informed consent all patients were evaluated by a trained psychiatrist.

\subsection{Measures}

\subsubsection{Personality pathology}

PD were evaluated using the Structured Interview for DSM-IV Personality (SIDP-IV) (Pfohl, Blum, \& Zimmerman, 1997). The SIDP-IV assesses each of the criteria for all personality disorders (PD) with one or more questions, which are then rated on a 4-point scale. In this study the number of criteria met (i.e., score $\geqslant 2$ ) were used as a dimensional measure of overall personality pathology (total number of PD criteria), Cluster A, B and C pathology, and definite PDs. During the enrolment time period of the study the raters $(n=4)$ met regularly with the first/last author to discuss the scored protocols; uncertainties were discussed until a consensus was reached. Independent ratings on ten conjoint interviews from the four raters were used to evaluate inter-rater reliabilities for PD criteria count. Intraclass correlations varied from 0.68 (for Schizoid and Narcissistic PD) to 0.92 (for Borderline PD).

\subsubsection{General psychopathology}

Current psychiatric disorders were assessed with the Structured Clinical Interview for DSM-IV-TR Axis I disorders Research Version (SCID-I/P-RV) (First, Spitzer, Gibbon, \& Williams, 2002). Current psychopathology severity was assessed by means of the General Severity Index (GSI) of the Symptom Checklist 90-revised (Derogatis, 1994; Prunas, Sarno, Preti, Madeddu, \& Perugini, 2011), a 90-item self-report inventory assessing nine primary symptom dimensions. The GSI is a global index of psychopathology that combines information concerning the number of symptoms reported with the intensity of perceived distress, thereby representing the best indicator of the current level or depth of an individual's disorder. The GSI internal consistency in this sample was .94.

\subsubsection{Alexithymia}

All subjects completed the Italian version of the twenty-item Toronto Alexithymia Scale (TAS-20), which showed good validity in both healthy and psychiatric subjects, irrespectively of gender (Bagby, Parker, \& Taylor, 1994; Bressi et al., 1996). The TAS-20 has a three-factor solution (i.e., Difficulty identifying feelings and bodily sensations, DIF; Difficulty describing feelings, DDF; Externally oriented thinking, EOT), which allows assessing both affectrelated (DIF, DDF) and cognitive (EOT) features of alexithymia. A total score is calculated by summing all items, after reversing scores for designated items; higher score reflects greater alexithymia. In this sample, the internal consistency was $\alpha=.84$ for TAS total and $\alpha=.77, \alpha=.63$ and $\alpha=.74$ for DIF, DDF and EOT.

\subsection{Statistical analysis}

Student's $t$-test for independent samples was applied to detect differences in TAS scores between genders, and Pearson's correlations were performed to examine their association with years of education, age, number and type of PD criteria, and GSI.

We next evaluated whether PD features interacted with current psychopathology severity (GSI) in predicting TAS scores using Hayes' (2013) bootstrapping procedure for conditional effects (SPSS-PROCESS macro, Model \#1). A series of moderation analyses were performed to evaluate whether any PD criteria (independent variables: overall PD criteria, Cluster A, B and C criteria) predicted alexithymic features (dependent variables: TAS total, DIF, DDF and EOT) depending on different levels of psychopathology severity (GSI: proposed moderator; low severity = GSI scores 1SD below the mean; moderate severity=mean GSI scores; high severity = GSI scores 1 SD above the mean). In order to facilitate the interpretation of the results, both the independent variables and the proposed moderator were mean centered prior to the analyses: 
thus, in all the equations the unstandardized regression coefficients (B) for each variable represent their simple conditional effects. - i.e., conditioned on the other variable being at the sample mean. For the PD criteria $\times$ GSI interaction terms, a 95\% confidence interval for $B$ not including zero signifies that the association between PD criteria and TAS scores varies depending on GSI ratings (Hayes, 2013). Demographic covariates found to be correlated with TAS scores in univariate analyses were controlled for in the regression models.

\section{Results}

\subsection{Sample characteristics}

Participants (males $=33.5 \%$ ) had a mean age of $37 \pm 10.7$ years, a mean level of education of $12 \pm 3.2$ years. $37.7 \%$ were single, $12 \%$ lived alone and $22.8 \%$ reported being unemployed. Axis I and II rates are shown in Table 1 . Nearly all included subjects (164 out of 167) received at least one Axis I diagnosis, reflecting the treatment-seeking nature of the sample, while 123 were diagnosed with PD. In terms of comorbidity, in this sample 121 patients (72.4\%) presented with both an Axis I and II disorder, 43 patients (25.7\%) had an Axis I disorder with no PD comorbidity, 2 patients had a PD diagnosis only, and one was free from any disorder.

All the examined variables were normally distributed except the number of Cluster A criteria met, which therefore was logtransformed in order to make the distribution acceptable (skewness $=.24$; kurtosis $=-1.1$ ).

\section{2. $P D$, symptom severity and alexithymia}

TAS total, DDF and EOT scores did not differ between females (TAS total: $56.2 \pm 14.7$; DDF: $14.6 \pm 5$; EOT: $19.4 \pm 6.3$ ) and males (TAS total: $55 \pm 15.7, t_{165}=-.47, \quad p=.6 ; \quad$ DDF: $14.2 \pm 5.6$, $t_{165}=-.43, p=.7$; EOT: $\left.21.1 \pm 6.8, t_{165}=1.52, p=.1\right)$, but DIF was

Table 1

DSM-IV Axis I and Axis II disorders rates in the study sample $(N=167)$.

\begin{tabular}{|c|c|c|}
\hline Type of disorder & $N$ & $\%$ \\
\hline Any Axis I Disorder & 164 & 98.2 \\
\hline One Axis I diagnosis & 127 & 76 \\
\hline$\geqslant$ Two Axis I diagnoses & 37 & 22.2 \\
\hline Anxiety Disorder & 84 & 50.3 \\
\hline Mood Disorder & 71 & 42.5 \\
\hline Eating Disorder ${ }^{1}$ & 27 & 16.2 \\
\hline Adjustment Disorder & 17 & 10.2 \\
\hline Somatoform Disorder & 5 & 3 \\
\hline Brief Psychotic Disorders & 5 & 3 \\
\hline Any personality disorder & 123 & 73.7 \\
\hline One PD diagnosis & 58 & 34.7 \\
\hline$\geqslant$ Two PD diagnoses & 55 & 33.1 \\
\hline Any Cluster A diagnosis & 29 & 17.4 \\
\hline Paranoid & 27 & 16.2 \\
\hline Schizotypal & 5 & 3 \\
\hline Schizoid & 3 & 1.9 \\
\hline Any Cluster B diagnosis & 59 & 35.3 \\
\hline Borderline & 34 & 20.4 \\
\hline Narcissistic & 26 & 15.6 \\
\hline Histrionic $^{2}$ & 15 & 9 \\
\hline Antisocial $^{3}$ & 4 & 2.4 \\
\hline Any Cluster C PD diagnosis & 73 & 43.7 \\
\hline Obsessive-Compulsive & 36 & 21.6 \\
\hline Avoidant & 27 & 16.2 \\
\hline Dependent & 27 & 16.2 \\
\hline Any adjunctive PD diagnosis ${ }^{a}$ & 23 & 13.8 \\
\hline
\end{tabular}

No other between-genders differences were found.

Self-defeating, Negativistic, Depressive PD.

$126=$ females, $1=$ male, $p<.00$.

$215=$ females, $0=$ males, $p=.04$

34 males, $0=$ females, $p=.02$. higher among female participants $(22.3 \pm 7$ vs $19.4 \pm 6.1$, $\left.t_{165}=-2.6, p=.01\right)$. Age was unrelated with any TAS indices, but educational level was inversely related with TAS total and EOT. GSI was associated with increasing scores on all the alexithymia factors. The overall number of PD criteria and Cluster $C$ criteria were associated with all TAS indices, while Cluster A criteria correlated only with TAS total and DIF scores, and Cluster B criteria with TAS total and DDF scores.

The results of the bootstrapping moderation analyses, after covarying for age and years of education where appropriate, are reported in Table 3.

\subsubsection{Overall PD criteria and alexithymia}

GSI interacted with overall PD criteria in predicting TAS total and EOT scores. PD criteria were associated with TAS total scores only at low $(B=.8, \quad C I=.24-1.36, p=.006)$ and average $(B=.45$, $\mathrm{CI}=.15-.76, p=.003$ ) levels of GSI, but not at high levels of GSI $(B=.11, C I=-.17$ to $.39, p=.44)$ (Fig. 1a). Similarly, overall PD criteria predicted EOT only at low $(B=.37, \mathrm{CI}=.1-.66, p=.01)$ and average $(B=.17, \mathrm{CI}=.002-.33, p=.05)$ levels of GSI, but not at high levels of GSI $(B=-.03, \mathrm{CI}=-.3$ to $.16, p=.74)$ (Fig. 1b). Total PD criteria were unrelated with DIF or DDF at any GSI level. Thus, general psychopathology severity moderated the link between overall PD criteria and TAS total and EOT scores: at high levels of psychopathology distress the presence of PD features makes little or no contribution to patients' alexithymic difficulties, which are mainly fostered by their comorbid psychiatric symptoms severity. However, at low levels of current psychopathology distress such difficulties are specifically associated with increasing number of PD criteria.

\subsubsection{Cluster A PD criteria and alexithymia}

Cluster A criteria and the Cluster A criteria $\times$ GSI interaction had no significant effect on any TAS indices. Since Coolidge et al. (2013) reported an association between alexithymia and paranoid and schizoid PD traits, we conducted separate analyses for schizoid, schizotypal and paranoid criteria, but none of them predicted any TAS factor at any GSI level. Thus, Cluster A criteria were unrelated to alexithymia, and this relationship did not vary as a function of general psychopathology severity.

\subsubsection{Cluster B PD criteria and alexithymia}

Cluster B criteria were unrelated with any TAS factor at any GSI level. Since these results were not consistent with previous findings that alexithymia is connected with BPD or BPD traits (Domes et al., 2011; Joyce et al., 2013; New et al., 2012), we next examined whether any individual Cluster B PD separately predicted TAS ratings. Antisocial, histrionic and narcissistic PD criteria were unrelated with TAS scores at any level of GSI. However, the interaction term BPD criteria $\times$ GSI significantly predicted EOT $\left(B=-.85, \mathrm{CI}=-1.53\right.$ to $\left.-.16, p=.01 ; R^{2}=.10, p=.03\right)$ : BPD criteria predicted greater EOT only when GSI was low $(B=.84, \mathrm{CI}=.01-1.7$, $p=.05)$, but not average $(B=.20, \mathrm{CI}=-.35$ to $.75, p=.5)$ or high ( $B=-.44, \mathrm{CI}=-.11$ to $.23, p=.17$ ) (Fig. 2). Thus, while in patients with high psychopathology distress the presence of BPD features does not contribute to increasing EOT, among patients with low symptom severity, BPD traits are associated with greater EOT.

\subsubsection{Cluster C PD criteria and alexithymia}

Cluster C criteria were associated with TAS total, DDF and EOT scores at any level of GSI (Fig. 3). Supplementary analyses conducted to establish which specific Cluster C PD was linked with alexithymia revealed that whereas obsessive-compulsive criteria were unrelated to any TAS indices, avoidant PD criteria significantly predicted TAS total score $(B=2.06, \mathrm{CI}=.45-3.68, p=.01$; $\left.R^{2}=.28, p<.001\right)$, DDF $\left(B=.66, \mathrm{CI}=.05-1.26, p=.03 ; R^{2}=.12\right.$, $p=.002)$ and EOT $\left(B=.96, \mathrm{CI}=.28-1.6, p=.006 ; R^{2}=.13, p=.004\right)$, 
Table 2

Descriptive statistics and Pearson's correlations among TAS scores, personality disorders criteria, and demographic and clinical variables.

\begin{tabular}{|c|c|c|c|c|c|c|c|c|c|c|c|}
\hline Variables & Mean \pm SD & 1. & 2. & 3. & 4. & 5. & 6. & 7. & 8. & 9. & 10. \\
\hline 1. Cluster A PD criteria & $2.29 \pm 2.7$ & - & & & & & & & & & \\
\hline 2. Cluster B PD criteria & $5.82 \pm 4.8$ & .14 & - & & & & & & & & \\
\hline 3. Cluster C PD criteria & $5.31 \pm 3.8$ & $.21^{* *}$ & -.07 & - & & & & & & & \\
\hline 4. Total PD criteria & $17.19 \pm 9.1$ & $.52^{* *}$ & $.60^{* *}$ & $.63^{* *}$ & - & & & & & & \\
\hline 5. Age & $37 \pm 10.8$ & -.07 & .03 & -.13 & -.04 & - & & & & & \\
\hline 6. Years of education & $12.04 \pm 3.2$ & -.13 & .02 & .04 & -.06 & $-.26^{* *}$ & - & & & & \\
\hline 7. CL-90-R GSI & $1.23 \pm 0.7$ & .03 & $.34^{* *}$ & .17 & $.33^{* *}$ & .09 & -.11 & - & & & \\
\hline 8. TAS total score & $56 \pm 15$ & $.19^{* *}$ & $.15^{*}$ & $.29^{* *}$ & $.38^{* *}$ & .01 & $-.19^{*}$ & $.46^{* *}$ & - & & \\
\hline 9. TAS DIF score & $21.3 \pm 6.9$ & .14 & $.29^{* *}$ & $.24^{* * *}$ & $.43^{* *}$ & .002 & -.12 & $.59^{* *}$ & $.82^{* *}$ & - & \\
\hline 10. TAS DDF score & $14.45 \pm 5.2$ & $.19^{*}$ & .06 & $.30^{* *}$ & $.31^{* *}$ & -.03 & -.11 & $.27^{* *}$ & $.82^{* *}$ & $.55^{* *}$ & \\
\hline 11. TAS EOT score & $20 \pm 6.5$ & .12 & -.01 & $.21^{* * *}$ & $.17^{*}$ & .04 & $-.22^{* *}$ & $.23^{*}$ & $.74^{* *}$ & $.37^{* *}$ & $.45^{* *}$ \\
\hline
\end{tabular}

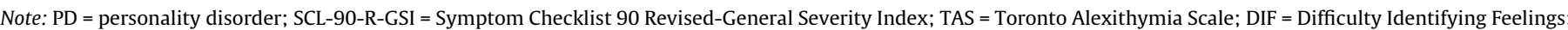
DDF = Difficulty Describing Feelings; EOT = Externally Oriented Thinking.

* $p \leqslant .05$.

$p \leqslant .01$.

Table 3

Association of TAS scores with PD criteria, GSI and their interaction.

\begin{tabular}{|c|c|c|c|c|c|c|c|c|}
\hline \multirow[t]{3}{*}{ Independent variables } & \multicolumn{8}{|c|}{ Dependent variables } \\
\hline & \multicolumn{2}{|c|}{ TAS total score ${ }^{\mathrm{b}}$} & \multicolumn{2}{|l|}{ DIF $^{\mathrm{a}}$} & \multicolumn{2}{|l|}{ DDF } & \multicolumn{2}{|l|}{$\mathrm{EOT}^{\mathrm{b}}$} \\
\hline & $B$ & $95 \% \mathrm{CI}$ & $B$ & $95 \% \mathrm{CI}$ & $B$ & $95 \% \mathrm{CI}$ & $B$ & $95 \% \mathrm{CI}$ \\
\hline $\begin{array}{l}\text { Overall PD criteria } \\
\text { SCL-90-R GSI } \\
\text { Overall PD criteria } \times \text { GSI } \\
\text { Regression Model } \mathrm{R}^{2}\end{array}$ & $\begin{array}{l}.45^{* *} \\
7.42^{* * *} \\
-.46^{*} \\
.29^{* * *}\end{array}$ & $\begin{array}{l}.15-.76 \\
2.97-11.87 \\
-.9 \text { to }-.02\end{array}$ & $\begin{array}{l}.19 \\
4.38^{* * *} \\
-.06 \\
.43^{* * *}\end{array}$ & $\begin{array}{l}-.01 \text { to } .36 \\
2.49-6.26 \\
-.29 \text { to } .16\end{array}$ & $\begin{array}{l}.08 \\
1.53^{*} \\
-.11 \\
.10^{*}\end{array}$ & $\begin{array}{l}-.04 \text { to } .21 \\
.07-2.30 \\
-.28 \text { to } .06\end{array}$ & $\begin{array}{l}.17^{*} \\
1.17 \\
-.27^{*} \\
.13^{* *}\end{array}$ & $\begin{array}{l}.002-.33 \\
-1.02 \text { to } 3.37 \\
-.51 \text { to }-.02\end{array}$ \\
\hline $\begin{array}{l}\text { Cluster A PD criteria } \\
\text { SCL-90-R GSI } \\
\text { Cluster A criteria } \times \text { GSI } \\
\text { Regression model } \text { R }^{2}\end{array}$ & $\begin{array}{l}1.04 \\
9.16^{* * *} \\
-.30 \\
.51^{* * *}\end{array}$ & $\begin{array}{l}-.58 \text { to } 2.66 \\
4.67-13.65 \\
-2.47 \text { to } 1.87\end{array}$ & $\begin{array}{l}.44 \\
5.03^{* * * *} \\
.03 \\
.41^{* * *}\end{array}$ & $\begin{array}{l}-.1 \text { to } .97 \\
3.3-6.77 \\
-.68 \text { to } .73\end{array}$ & $\begin{array}{l}.32 \\
1.84^{*} \\
-.17 \\
.10^{*}\end{array}$ & $\begin{array}{l}-.19 \text { to } .84 \\
.42-3.25 \\
-.83 \text { to } .49\end{array}$ & $\begin{array}{l}.21 \\
1.85 \\
-.17 \\
.08\end{array}$ & $\begin{array}{l}-.56 \text { to } .97 \\
-.32 \text { to } 4.02 \\
-1.22 \text { to } .87\end{array}$ \\
\hline $\begin{array}{l}\text { Cluster B PD criteria } \\
\text { SCL-90-R GSI } \\
\text { Cluster B criteria } \times \text { GSI } \\
\text { Regression model } \text { R }^{2}\end{array}$ & $\begin{array}{l}-.1 \\
9.69^{* * *} \\
-.24 \\
.24^{* *}\end{array}$ & $\begin{array}{l}-.76 \text { to } .57 \\
5-14.4 \\
-1.05 \text { to } .56\end{array}$ & $\begin{array}{l}.19 \\
4.70^{* * * *} \\
-.003 \\
.39^{* * * *}\end{array}$ & $\begin{array}{l}-.11 \text { to } .50 \\
2.81-6.58 \\
-.36 \text { to } .36\end{array}$ & $\begin{array}{l}-.17 \\
2.27^{* * *} \\
.02 \\
.09^{* *}\end{array}$ & $\begin{array}{l}-.39 \text { to } .06 \\
.91-3.62 \\
-.28 \text { to } .32\end{array}$ & $\begin{array}{l}-.15 \\
2.35^{*} \\
-.23 \\
.11\end{array}$ & $\begin{array}{l}-.43 \text { to } .14 \\
.08-4.61 \\
-.54 \text { to } .07\end{array}$ \\
\hline $\begin{array}{l}\text { Cluster C PD criteria } \\
\text { SCL-90-R GSI } \\
\text { Cluster C criteria } \times \text { GSI } \\
\text { Regression model } \mathrm{R}^{2}\end{array}$ & $\begin{array}{l}1.18^{* *} \\
8.35^{* * *} \\
-.06 \\
.31^{* * * *}\end{array}$ & $\begin{array}{l}.43-1.93 \\
4.18-12.5 \\
-1.31 \text { to } 1.18\end{array}$ & $\begin{array}{l}.28 \\
4.91^{* * *} \\
-.03 \\
.40^{* * * *}\end{array}$ & $\begin{array}{l}-.03 \text { to } .59 \\
3.17-6.66 \\
-.51 \text { to } .44\end{array}$ & $\begin{array}{l}.36^{*} \\
1.57^{*} \\
-.11 \\
.14^{* *}\end{array}$ & $\begin{array}{l}.05-.67 \\
.12-3.01 \\
-.58 \text { to } .35\end{array}$ & $\begin{array}{l}.58^{* * *} \\
1.45 \\
.09 \\
.18^{* *}\end{array}$ & $\begin{array}{l}.24-.91 \\
-.60 \text { to } 3.51 \\
-.46 \text { to } .64\end{array}$ \\
\hline
\end{tabular}

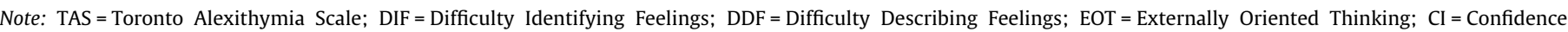
Interval; PD = personality disorder; SCL-90-R-GSI = Symptom Checklist-90 Revised-General Severity Index.

${ }^{*} p \leqslant .05$.

*** $p \leqslant .01$.

**** $p \leqslant .001$.

a Gender as a covariate: significant where Cluster $\mathrm{A}$ and $\mathrm{B}$ criteria were entered as independent variables (respectively $B=2.5, p=.03$, CI $=.27-4.8$; and $B=2.51, p=.04$, $\mathrm{CI}=.16-4.8)$.

b Years of education as a covariate (n.s.).

and dependent PD criteria predicted TAS total score $(B=1.81$, $\left.\mathrm{CI}=.38-3.24, p=.01 ; R^{2}=.27, p<.001\right)$ and EOT $(B=1.2, \mathrm{CI}=.49$ $\left.1.90, p=.001 ; R^{2}=.10, p=.01\right)$. No Cluster C PD criteria $\times$ GSI interaction term was significant in any of the models tested. Thus, Cluster C criteria were associated with alexithymic features, and the strength of such relationship did not vary as a function of general psychopathology severity.

\section{Discussion}

This study investigated whether, among treatment-seeking psychiatric outpatients, personality disturbances are associated with affective and cognitive facets of alexithymia depending on varying levels of current psychopathology severity.

\subsection{Three main findings emerged}

First, in terms of the relationship of overall personality pathology with alexithymic features, total PD criteria were associated with greater overall alexithymia only at mild/moderate levels of psychopathology distress (Fig. 1a). These data clarify previous contrasting findings of an association, or lack thereof, between alexithymia and PD. For patients with severe psychological distress alexithymic difficulties are mainly fostered by their non-PD symptom burden; however, patients with increasing PD features show alexithymic deficits even when their psychological distress is low, confirming that both the presence of PD and the severity of other psychiatric symptoms are important variables when explaining the presence of alexithymia in psychiatric samples (Honkalampi et al., 2001). Importantly, PD features were specifically associated with the cognitive aspect of alexithymia (externally oriented thinking) (Fig. $1 \mathrm{~b}$ ), reflecting the inability to analyze one's emotions and other aspects of inner experience. This tendency to avoid affective thinking results in a preference for the external details of everyday life at the expenses of object relations, which can ultimately deprive the individual of the ability to empathize with significant others (Vorst \& Bermond, 2001). Empathic dysfunctions are central for a personality disorder diagnosis 

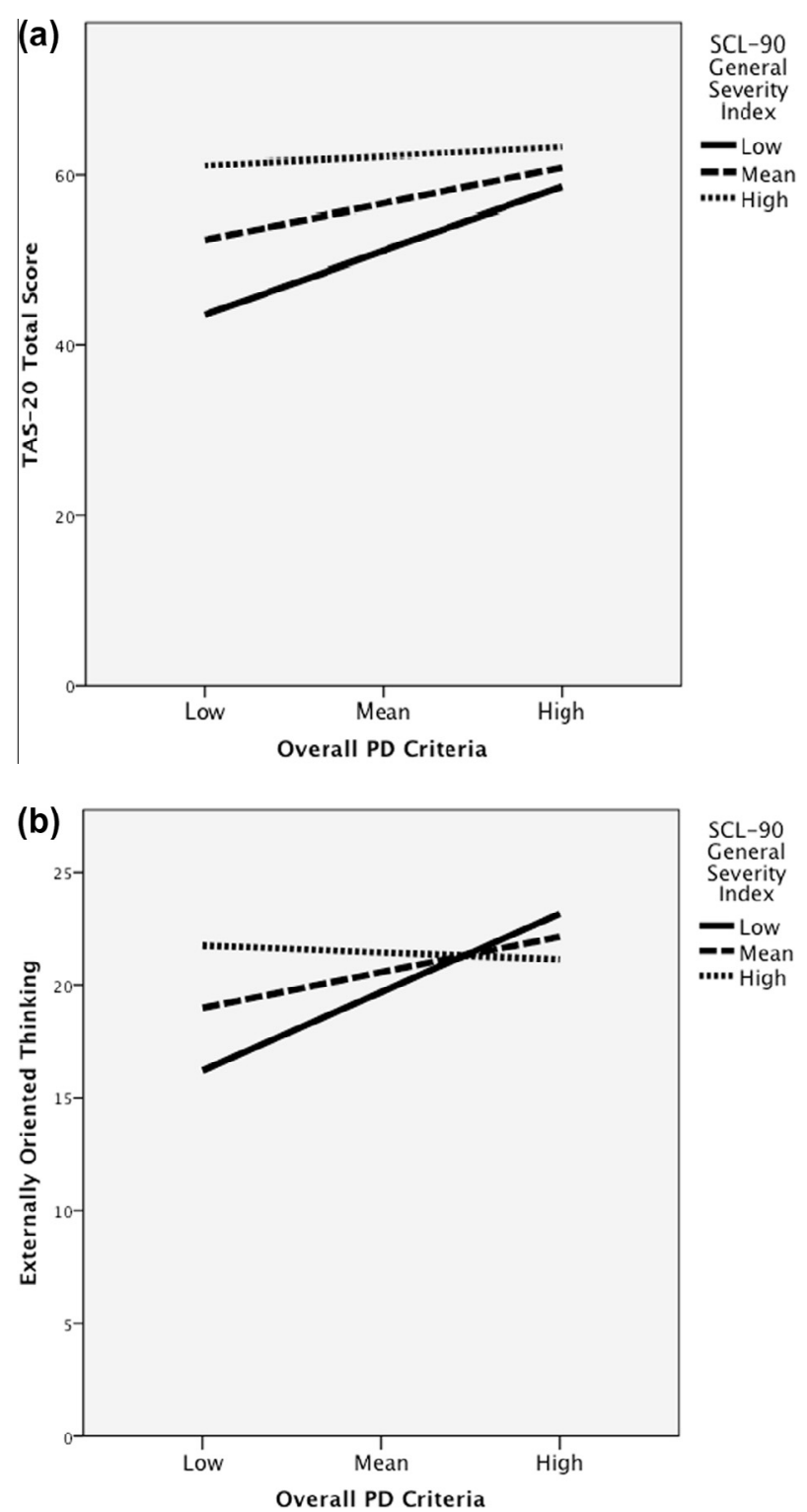

Fig. 1. Interaction between overall PD criteria and current psychopathology severity in predicting alexithymic features. (a). Moderation of PD criteria/TAS total score by SCL-90 GSI. (b). Moderation of PD criteria/EOT score by SCL-90 GSI. Note: $\mathrm{PD}=$ Personality Disorder; TAS = Toronto Alexithymia Scale; EOT = Externally Oriented Thinking; SCL-90 = Symptom Checklist-90-Revised. Low $=-1$ SD below the mean; High $=+1$ SD above the mean.

(APA, 2013). Individuals with alexithymia show reduced activation in brain areas associated with cognitive/mature empathy (Moriguchi et al., 2007), and EOT in particular is inversely related with perspective taking regardless of dysphoric mood (Grynberg et al., 2010). Thus, the extensive empathic difficulties often exhibited by patients with personality disorders could be related with this concrete, reality based cognitive style that ultimately prevent them to recognize others' perspectives. Conversely, in this study the affective components of alexithymia (i.e., impaired emotional awareness and expression) were mainly related with psychopathology severity across all the regression models tested, but much less so with PD (Table 3), suggesting that among patients with personality disturbances these deficits represent only a correlate of the current state of distress, rather than a stable feature of personality pathology.

Second, in terms of the relation of alexithymia with specific PD clusters, only Cluster C criteria (specifically avoidant and

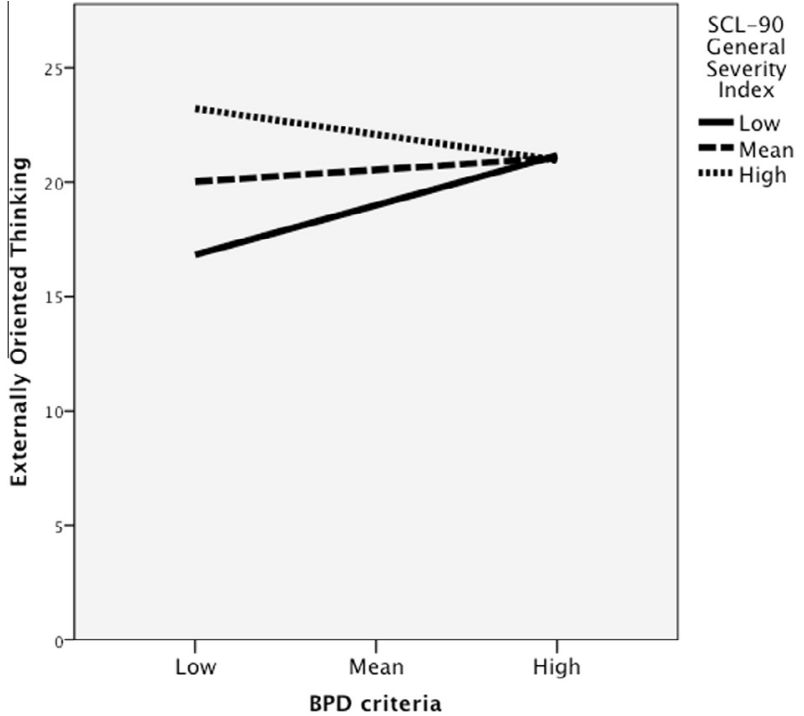

Fig. 2. Interaction between BPD criteria and current psychopathology severity in predicting EOT. Note: $\mathrm{BPD}=$ Borderline Personality Disorder; EOT = Externally Oriented Thinking; SCL-90 = Symptom Checklist-90-Revised. Low $=-1$ SD below the mean; High $=+1 \mathrm{SD}$ above the mean.

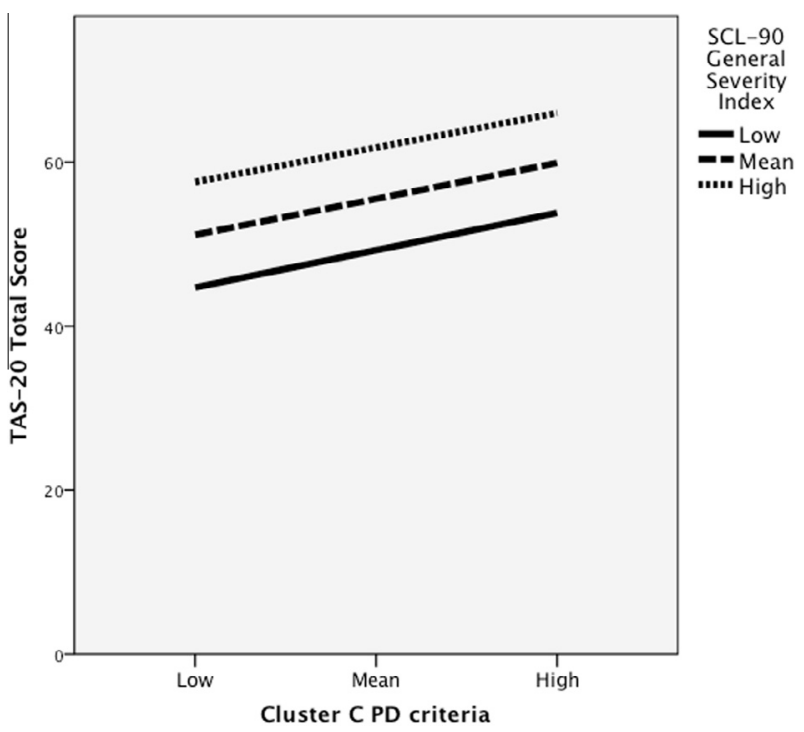

Fig. 3. Lack of interaction between Cluster C PD criteria and current psychopathology severity in predicting TAS total score. Note: $\mathrm{PD}=$ Personality Disorder; TAS$20=$ Toronto Alexithymia Scale; SCL-90 = Symptom Checklist-90-Revised. Low $=-1$ SD below the mean; High $=+1$ SD above the mean.

dependent criteria) were associated with overall and, particularly, cognitive alexithymic features at any level of comorbid psychopathology severity (Fig. 3), while Cluster A and B criteria were not. These results support the view that alexithymic disturbances are not homogeneous among individuals with personality disorders once psychopathology severity is controlled for (Nicolò et al., 2011) and confirm a specific association between alexithymia and Cluster C PD/trait anxiety (Bach et al., 1994; Honkalampi et al., 2001; Joyce et al., 2013; Nicolò et al., 2011; Sexton et al., 1998). However, our finding might also be partly explained by the lesser symptom burden often showed by Cluster $C$ patients when compared to other personality disorders (McGlashan et al., 2000), as suggested by the lack of correlation between Cluster $\mathrm{C}$ criteria and GSI (Table 2). Further, obsessive-compulsive features were unrelated with any alexithymia indices, supporting the notion that 
at least some patients with obsessive-compulsive personality disorder may exhibit lesser personal/interpersonal impairment than other PD patients (Shedler \& Westen, 2004; Skodol et al., 2011).

Third, in this study borderline pathology was also associated with greater externally oriented thinking at low but not moderate/high symptom severity (Fig. 2). Thus, for borderline patients with moderate/severe psychopathology current distress is likely to contribute to their reality-based cognitive style to a greater extent than their borderline traits. However, the association between increasing borderline features and greater externally oriented thinking among individuals with mild symptom distress indicates that a relative inability to reflect upon one's own and others' inner experiences also represents a trait-like feature of BPD. This is in keeping with previous findings of impaired perspective taking, emotional clarity and mentalization in BPD (Dziobek et al., 2011; Fonagy \& Bateman, 2008; Leible \& Snell, 2004) and supports the utility of interventions improving reflective functioning (Levy et al., 2006). At the same time, these results contradict prior associations between difficulty identifying feelings and BPD (Sexton et al., 1998), which suggested that BPD patients' problem with emotion labeling would lead to misinterpretations of social signs and increasing interpersonal dysfunction (Domes et al., 2011; Joyce et al., 2013; New et al., 2012). Nonetheless, Hart, McGowan, Minati, and Critchley (2013) recently demonstrated that deficits in labeling the physiological sensations of emotions do not represent specific markers of BPD. Accordingly, in this study BPD criteria were unrelated with emotional awareness (DIF) at any level of GSI, suggesting that these patients' confusion between emotional and bodily states might be reduced by decreasing their current symptom distress.

This study is limited by the use of a self-report measure of alexithymia, which makes it necessary to replicate these findings by employing structured interviews or observers' rating scales. Longitudinal studies should also examine whether EOT is still associated with PD features among patients who eventually remit from their concurrent non-PD disorders. A major strength of the study is its 'real world', reliably diagnosed clinical sample, with a wide range of $\mathrm{PD} /$ other psychiatric disorders comorbidity and representative of Italian psychiatric services users. If confirmed, these results can be helpful for clinicians working with personality disordered patients. Interventions aimed at reducing symptom distress may decrease patients' difficulties expressing and discussing emotions that may be needed for addressing PD pathology. In addition, interventions that specifically address a concrete style of relating to others and the capacity to analyze inner feelings may be important to reduce the interpersonal dysfunction in patients with avoidant, dependent and borderline features.

\section{Conclusion}

These results suggest that PDs in general are not invariably associated, per se, with a deficit in identifying and communicating emotions. Rather, such difficulties are likely to be fostered by their comorbid psychiatric symptom severity. However, individuals with increasing overall personality disorder features criteria and particularly avoidant, dependent and borderline traits might find it hard focusing on their own and others' inner feelings, even when their symptom distress is low. Thus, PD patients might benefit from interventions aimed at reducing their alexithymic features by targeting both their comorbid psychiatric symptoms and their poor focus on internal reality, thereby increasing their social-cognitive skills and favouring their interpersonal adjustment.

\section{References}

American Psychiatric Association (2013). Diagnostic and statistical manual of mental disorders (5th ed.). Washington, DC: American Psychiatric Publishing.
Bach, M., de Zwaan, M., Ackard, D., Nutzinger, D. O., \& Mitchell, J. E. (1994). Alexithymia: Relationship to personality disorders. Comprehensive Psychiatry, 35, 239-243.

Bagby, R. M., Parker, J. D. A., \& Taylor, G. J. (1994). The twenty-item Toronto Alexithymia Scale. I. Item selection and cross validation of the factor structure. Journal of Psychosomatic Research, 38, 23-32.

Berenbaum, H. (1996). Childhood abuse, alexithymia and personality disorder Journal of Psychosomatic Research, 41, 585-595.

Bressi, C., Taylor, G., Parker, J., Bressi, S., Brambilla, V., Aguglia, E., et al. (1996). Cross validation of the factor structure of the 20 -item Toronto Alexithymia Scale: An Italian multicenter study. Journal of Psychosomatic Research, 41, 551-559.

Choi-Kain, L. W., \& Gunderson, J. G. (2008). Mentalization: Ontogeny, assessment, and application in the treatment of borderline personality disorder. American Journal of Psychiatry, 165, 1127-1135. http://dx.doi.org/10.1176/ appi.ajp.2008.07081360.

Coolidge, F. L., Estey, A. J., Segal, D. L., \& Marle, P. D. (2013). Are alexithymia and schizoid personality disorder synonymous diagnoses? Comprehensive Psychiatry, 54, 141-148. http://dx.doi.org/10.1016/j.comppsych.2012.07.005.

De Panfilis, C., Salvatore, P., Marchesi, C., Cazzolla, R., Tonna, M., \& Maggini, C. (2008). Parental bonding and personality disorder: The mediating role of alexithymia. Journal of Personality Disorder, 22, 496-508. http://dx.doi.org/ 10.1521/pedi.2008.22.5.496.

Derogatis, L. R. (1994). Symptom Checklist-90-R: Administration, scoring and procedures manual (3rd ed.). Minneapolis, MN: National Computer Systems.

Di Maggio, G., Carcione, A., Nicolò, G., Lysaker, P. H., d'Angerio, S., Conti, M. L., et al. (2013). Differences between axes depend on where you set the bar: Associations among symptoms, interpersonal relationship and alexithymia with number of personality disorder criteria. Journal of Personality Disorders, 27 371-382. http://dx.doi.org/10.1521/pedi_2012_26_043.

Domes, G., Grabe, H. J., Czieschnek, D., Heinrichs, M., \& Herpertz, S. C. (2011) Alexithymic traits and facial emotion recognition in borderline personality disorder. Psychotherapy and Psychosomatics, 80, 383-385. http://dx.doi.org/ $10.1159 / 000325828$.

Dziobek, I., Preissler, S., Grozdanovic, Z., Heuser, I., Heekren, H. R., \& Roepke, S. (2011). Neuronal correlates of altered empathy and social cognition in borderline personality disorder. Neuroimage, 57, 539-548. http://dx.doi.org/ 10.1016/j.neuroimage.2011.05.005.

First, M. B., Spitzer, R. L., Gibbon, M., \& Williams, J. B. W. (2002). Structured clinica interview for DSM-IV-TR axis-I disorders, research version, patient edition (SCID-I/ $P-R V)$. New York: Biometrics Research Department, New York State Psychiatric Institute. november 2002 revision.

Fonagy, P., \& Bateman, A. (2008). The development of borderline personality disorder - A mentalizing model. Journal of Personality Disorders, 22, 4-21. http:// dx.doi.org/10.1521/pedi.2008.22.1.4.

Grabe, H. J., Spitzer, C., \& Freyberger, H. J. (2001). Alexithymia and the temperament and character model of personality. Psychotherapy and Psychosomatics, 70 261-267.

Grynberg, D., Luminet, O., Corneille, O., Grèzes, J., \& Berthoz, S. (2010). Alexithymia in the interpersonal domain: A general deficit of empathy? Personality and Individual Differences, 49, 845-850. http://dx.doi.org/10.1016/j.paid.2010.07.013.

Guttman, H., \& Laporte, L. (2002). Alexithymia, empathy and psychological symptoms in a family context. Comprehensive Psychiatry, 43, 448-455.

Hart, N., McGowan, J., Minati, L., \& Critchley, H. D. (2013). Emotional regulation and bodily sensation: Interoceptive awareness is intact in borderline personality disorder. Journal of Personality Disorders, 27, 506-518. http://dx.doi.org/ 10.1521/pedi_2012_26_049.

Hayes, A. F. (2013). Introduction to mediation, moderation and conditional process analysis. A regression-based approach. New York: Guilford Press.

Honkalampi, K., Hintikka, J., Antikainen, R., Lehtonen, J., \& Viinamaki, H. (2001) Alexithymia in patients with major depressive disorder and comorbid cluster $C$ personality disorders: A 6-month follow-up study. Journal of Personality Disorders, 3, 245-254.

Joyce, A. S., Fujiwara, E., Cristall, M., Ruddy, C., \& Ogrodniczuk, J. S. (2013). Clinical correlates of alexithymia among patients with personality disorder. Psychotherapy Research, 23, 690-704. http://dx.doi.org/10.1080/ 10503307.2013.803628.

Leible, T. L., \& Snell, W. E. Jr., (2004). Borderline personality disorder and multiple aspects of emotional intelligence. Personality and individual differences, 37, 393-404.

Levy, K. N., Meehan, K. B., Kelly, K. M., Reynoso, J. S., Weber, M., Clarkin, J., et al. (2006). Change in attachment patterns and reflective function in a randomized control trial of transference-focused psychotherapy for borderline personality disorder. Journal of Consulting and Clinical Psychology, 74, 1027-1040.

Marchesi, C., Brusamonti, E., \& Maggini, C. (2000). Are alexithymia, depression, and anxiety distinct constructs in affective disorders? Journal of Psychosomatic Research, 49, 43-49.

Marchesi, C., Fontò, S., Balista, C., Cimmino, C., \& Maggini, C. (2005). Relationship between alexithymia and panic disorder: A longitudinal study to answer an open question. Psychotherapy and Psychosomatics, 74, 56-60.

Marchesi, C., Bertoni, S., Cantoni, A., \& Maggini, C. (2008). Is alexithymia a personality trait increasing the risk of depression? A prospective study evaluating alexithymia before, during and after a depressive episode. Psychological Medicine, 38, 1717-1722. http://dx.doi.org/10.1017/ S0033291708003073.

Marchesi, C., Ossola, P., Tonna, M., \& De Panfilis, C. (2014). The TAS-20 more likely measures negative affects rather than alexithymia itself in patients with major 
depression, panic disorder, eating disorders and substance use disorders. Comprehensive Psychiatry, 55, 972-978. http://dx.doi.org/10.1016/ j.comppsych.2013.12.008.

McGlashan, T. H., Grilo, C. M., Skodol, A. E., Gunderson, J. G., Shea, M. T., Morey, L. C., et al. (2000). The collaborative longitudinal personality disorders study: Baseline Axis I/II and II/II diagnostic co-occurrence. Acta Psychiatrica Scandinavica, 102, 256-264.

Moriguchi, Y., Decety, J., Ohnishi, T., Maeda, M., Mori, T., Nemoto, K., et al. (2007). Empathy and judging other's pain: An fMRI study of alexithymia. Cerebral Cortex, 17, 2223-2234.

New, A. S., Aanhet Rot, M., Ripoll, L. H., Perez-Rodriguez, M. M., Lazarus, S., et al (2012). Empathy and alexithymia in borderline personality disorder: Clinica and laboratory measures. Journal of Personality Disorders, 26, 660-675.

Nicolò, G., Semerari, A., Lysaker, P. H., Dimaggio, G., Conti, L., D’Angerio, S., et al (2011). Alexithymia in personality disorders: Correlations with symptoms and interpersonal functioning. Psychiatry Research, 190, 37-42. http://dx.doi.org 10.1016/j.psychres.2010.07.046

Pfohl, B., Blum, M., \& Zimmerman, M. (1997). Structured interview for DSM-IV personality. Washington, DC: American Psychiatric Press.
Prunas, A., Sarno, I., Preti, E., Madeddu, F., \& Perugini, M. (2011). Psychometric properties of the Italian version of the SCL-90-R: A study on a large community sample. European Psychiatry, 27, 591-597. http://dx.doi.org/10.1016/ j.eurpsy.2010.12.006.

Saarijavi, S., Salminen, J. K., \& Toikka, T. B. (2001). Alexithymia and depression: A 1year follow-up study in outpatients with major depression. Journal of Psychosomatic Research, 51, 729-733.

Sexton, M. C., Sunday, S. R., Hurt, S., \& Halmi, K. A. (1998). The relationship between alexithymia, depression, and Axis II psychopathology in eating disorder inpatients. International Journal of Eating Disorder, 23, 277-286.

Shedler, J., \& Westen, D. (2004). Refining personality disorder diagnosis: Integrating science and practice. American Journal of Psychiatry, 161, 1350-1365.

Skodol, A. E., Bender, D. M., Morey, L. C., Clark, L. A., Oldham, J. M., Alarcon, R. D., et al. (2011). Personality disorder types proposed for DSM-5. Journal of Personality Disorders, 25, 136-169. http://dx.doi.org/10.1521/pedi.2011.25.2.136.

Taylor, G. J., Bagby, R. M., \& Parker, J. D. A. (1997). Disorders of affect regulation. Alexithymia in medical and psychiatric illness. Cambridge University Press.

Vorst, H. C. M., \& Bermond, B. (2001). Validity and reliability of the Bermond-Vorst alexithymia questionnaire. Personality and Individual Differences, 30, 413-434. 